\title{
Nuclear Imaging of Bacterial Infection: The State of the Art and Future Directions
}

\author{
Ilona Polvoy ${ }^{1}$, Robert R. Flavell ${ }^{1}$, Oren S. Rosenberg ${ }^{2}$, Michael A. Ohliger ${ }^{1,3}$, and David M. Wilson ${ }^{1}$ \\ ${ }^{1}$ Department of Radiology and Biomedical Imaging, University of California, San Francisco, San Francisco, California; ${ }^{2}$ Department \\ of Medicine, University of California, San Francisco, San Francisco, California; and ${ }^{3}$ Department of Radiology, Zuckerberg San \\ Francisco General Hospital, San Francisco, California
}

\begin{abstract}
Learning Objectives: On successful completion of this activity, participants should be able to describe (1) the clinical justifications for using nuclear medicine techniques in imaging bacterial infections; (2) the mechanisms of nuclear imaging methods used to detect bacterial infections; and (3) the bacterial-metabolism specific imaging techniques currently under development.
\end{abstract}

Financial Disclosure: Dr. Ohliger travels and speaks for General Electric. The authors of this article have indicated no other relevant relationships that could be perceived as a real or apparent conflict of interest.

CME Credit: SNMMI is accredited by the Accreditation Council for Continuing Medical Education (ACCME) to sponsor continuing education for physicians. SNMMI designates each JNM continuing education article for a maximum of 2.0 AMA PRA Category 1 Credits. Physicians should claim only credit commensurate with the extent of their participation in the activity. For CE credit, SAM, and other credit types, participants can access this activity through the SNMMI website (http://www.snmmilearningcenter.org) through December 2023.

Increased mortality rates from infectious diseases is a growing public health concern. Successful management of acute bacterial infections requires early diagnosis and treatment, which are not always easy to achieve. Structural imaging techniques such as CT and MRI are often applied to this problem. However, these methods generally rely on secondary inflammatory changes and are frequently not specific to infection. The use of nuclear medicine techniques can add crucial complementary information, allowing visualization of infectious pathophysiology beyond morphologic imaging. This review will discuss the current structural and functional imaging techniques used for the diagnosis of bacterial infection and their roles in different clinical scenarios. We will also present several new radiotracers in development, with an emphasis on probes targeting bacteria-specific metabolism. As highlighted by the current coronavirus disease 2019 epidemic, caused by the novel severe acute respiratory syndrome coronavirus 2 , similar thinking may apply in imaging viral pathogens; for this case, prominent effects on host proteins, most notably angiotensin-converting enzyme 2, might also provide worthwhile imaging targets.

Key Words: infection; imaging; nuclear medicine; PET; SPECT

J Nucl Med 2020; 61:1708-1716

DOI: 10.2967/jnumed.120.244939

nfectious diseases are a pressing public health concern. The rise of multidrug-resistant bacteria, especially in health-careassociated infections, has resulted in increased mortality rates (1) despite the identification of new antimicrobial targets (2) and the focus on early diagnosis of disease. Although this early

Received Mar. 10, 2020; revision accepted Jun. 23, 2020

For correspondence or reprints contact: David Wilson, Department of Radiology and Biomedical Imaging, University of California, San Francisco, 505 Parnassus Ave., San Francisco, CA 94143.

E-mail: david.m.wilson@ucsf.edu

Published online Aug. 6, 2020.

COPYRIGHT (C) 2020 by the Society of Nuclear Medicine and Molecular Imaging. diagnosis is crucial for patient management, it is not always easy to achieve. Although clinical history, physical examination, blood cultures, or simple radiographs all assist in diagnosing infections, others require more complex imaging studies (3). One reason for this diagnostic difficulty is that infectious and inflammatory conditions have similar signs and symptoms, especially in patients with chronic infections, in patients with compromised immune systems, and in the elderly (4-6).

When more complex imaging is necessary, structural imaging techniques such as CT, MRI, and ultrasound are usually the next steps in the diagnostic approach. These techniques excel at identifying the presence of abnormal fluid, either within organs and other tissues or forming discrete collections (i.e., abscesses). This abnormal distribution of fluid is related to increased vasodilation and vascular permeability, resulting in tissue edema and stranding of normally fatty signal. However, these signs are nonspecific and might appear in infection as well as in other inflammatory conditions $(7,8)$. Additionally, anatomic changes that occur with chronic infection, such as bone destruction in osteomyelitis, weaken our ability to differentiate between active processes and treated disease $(8,9)$.

Nuclear medicine (NM) techniques such as SPECT and PET have also been applied to this problem. These methods allow visualization of infectious pathophysiology beyond structural imaging. The diagnostic accuracy of SPECT and PET is enhanced when structural modalities are used in tandem and can pinpoint the exact location of the pathology with higher resolution than NM alone (10). The proliferation of PET/CT, PET/MRI, and SPECT/ CT dual imaging therefore has great potential to address the field of infectious disease imaging.

In this review, we discuss the current imaging techniques for bacterial infection diagnosis, focusing on current NM methods, their limitations, and how they are applied to common medical scenarios. We also provide a brief review of novel radiotracers currently in development, highlighting tracers that target bacterial metabolism.

\section{IMAGING INFECTION: THE STATE OF THE ART}

Imaging studies are frequently used to support the diagnosis of infection in acutely ill patients. Structural imaging studies include 
plain radiography, ultrasound, CT, and MRI. These methods can establish the presence of abnormal tissue or fluid collections that often accompany bacterial infection. For example, point-of-care ultrasound can be an effective tool for identifying the source of an infection as early as in the emergency department (11). Chest radiography is used to detect consolidations, which are normally aerated portions of lung that are filled with liquid and tissue. Similarly, CT and MRI can show the presence of inflammation and abscesses. These structural methods can be complemented by NM techniques (PET and SPECT) that represent a type of molecular imaging whereby biochemical and physiologic abnormalities can be investigated. PET and SPECT are most helpful for equivocal cases, or for those in which tissue sampling is difficult. In this section, we summarize both structural techniques and current clinical NM methodologies (Fig. 1).

\section{Structural Imaging Techniques}

The most commonly used noninvasive technique for the evaluation of tissue structure is the CT scan. This widely available examination produces high-resolution images and is considered the first-line choice in multiple clinical scenarios (12). However, CT has poor sensitivity for detecting early infection because of the frequent absence of anatomic changes. Similarly, later in the disease, persistent anatomic abnormalities often mask chronic active infection. Moreover, ionizing radiation and the sensitivity of some patients to iodinated contrast medium also limit the use of CT $(6,12,13)$. In contrast, MRI does not require ionizing radiation (12). It provides excellent soft-tissue distinction even in the absence of contrast medium (10). MRI is useful for the assessment of noncalcified tissues such as ligaments and viscera and is highly sensitive to tissue water content, allowing the diagnosis of inflammation, neoplasms, ischemia, and other abnormalities (14). However, MRI has low value in the evaluation of patients after surgery, and it can be potentially risky for patients with metallic implants or pacemakers $(6,9)$.

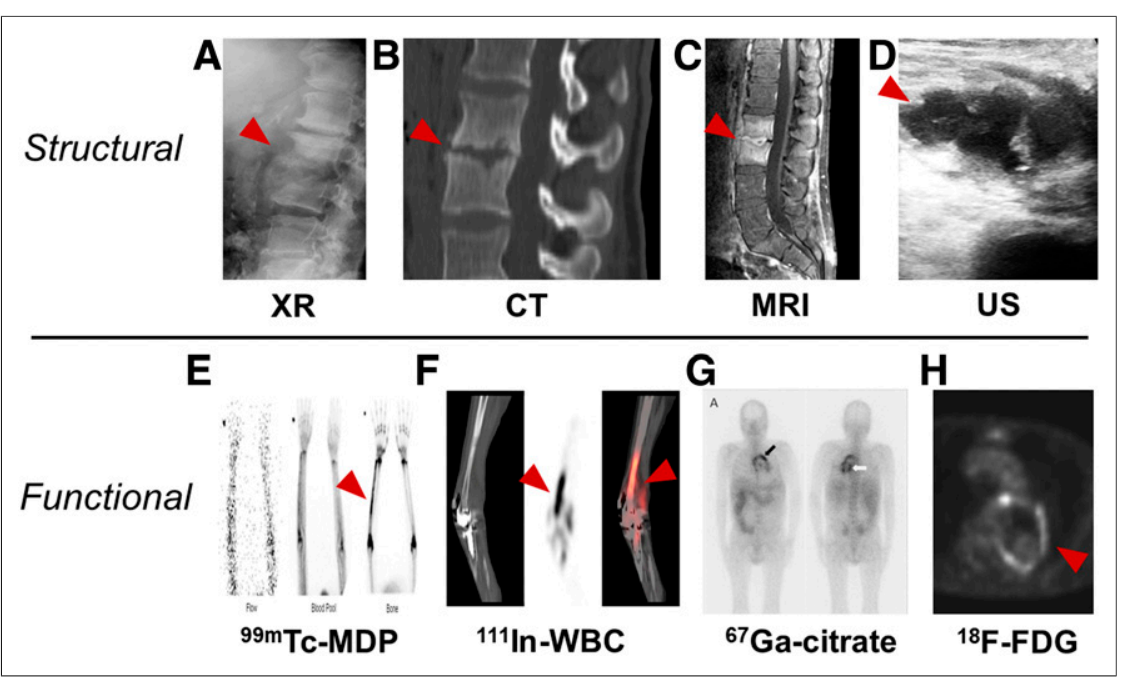

FIGURE 1. Examples of structural and functional imaging used in diagnosis of infection. (A) Plain radiography of 55-y-old man with diskitis-osteomyelitis after corpectomy. (B and C) CT and MRI of 23-y-old man with chronic diskitis-osteomyelitis. (D) Ultrasound of 4-y-old boy with perforated appendicitis and associated abscess. (E) ${ }^{99 m T C}$-methylene diphosphonate bone scan of right ulnar osteomyelitis. (Reprinted with permission of (25).) (F) ${ }^{111} \mathrm{In}$-WBC SPECT/CT of infected right knee arthroplasty. (Reprinted with permission of (25).) (G) ${ }^{67} \mathrm{Ga}$-citrate scan of 61 -y-old man with infected endovascular graft of aortic arch. (Reprinted with permission of (74).) (H) ${ }^{18} \mathrm{~F}$-FDG/PET of 66-y-old man with infected thoracic aorta endograft. $(A-D)$ Red arrowhead indicates point of infection; $(E-H)$ red arrowhead indicates increased tracer uptake.

\section{Functional Imaging Techniques}

In recent years there has been a growing interest in applying NM techniques (e.g., SPECT and PET) to the field of infectious disease $(15,16)$, anticipating that metabolic abnormalities precede morphologic changes identified using structural imaging $(17,18)$. Moreover, the introduction of hybrid NM and structural technol(e.g., PET/CT) has allowed better resolution for more prealization of pathology, making this approach highly appealing $(19,20)$. In the next section, we will discuss the current clinically available applications of NM to infection. Those techare summarized in Table 1.

Bone Scintigraphy. Bone scintigraphy is a highly sensitive technique $(20,21)$ that uses a labeled diphosphonate, most commonly $99 \mathrm{~m}$ Tc-MDP, as a marker for active bone formation. Its uptake in pathologic processes depends on 2 main factors: bone turnover and perfusion (18-20). These are abnormal in most pathologic bone conditions, including infectious, traumatic, and neoplastic conditions, and therefore bone scintigraphy often requires a complementary imaging method to achieve diagnosis (20). Bone scintigraphy is usually performed via a single-phase or, less commonly, a triple-phase test, indicated by the suspected pathology. the triple-phase bone scan (TPBS) uses 3 different time points: the flow phase, which is immediately after the injection and demonstrates perfusion at the inflammation site, the blood pool phase, phase, which illustrates the bone remodeling process after most of the soft-tissue activity has washed out (19). TPBS is especially valuable when trying to differentiate bone infection from other example, soft-tissue infection, unlike osteomyelitis, will not show tracer accumulation in the bone uptake phase (19).

Scintigraphy with Labeled Autologous White Blood Cells (WBC Scan). The WBC scan is a fairly common and sensitive technique that detects tagged WBC cells migrating to the site of infection through chemotaxis and diapedesis $(3,22,23)$. It is considered the gold standard modality in many infectious scenarios, yet it has several drawbacks (23). The WBC scan can be a laborious and time-consuming procedure that exposes medical personal to blood products. It requires careful patient identification and extraction and separation of WBCs from a whole-blood sample. Next, the WBCs undergo incubation with a radiotracer, usually ${ }^{99 \mathrm{~m}} \mathrm{Tc}$ or ${ }^{111} \mathrm{In}$; washing to remove any unbound radiotracer; and reinjection of cells into the patient before imaging $(22,24)$. This examination is unsuitable for opportunistic or chronic infection because of the lymphocytic sensitivity to radiation and the requirement that the patient have at least 2,000 leukocytes (cells $/ \mu \mathrm{L}$ ), making it unfit for patients with granulocytopenia $(22,24,25)$. Moreover, the phagocytosis of radiolabeled leukocytes by reticuloendothelial cells in the 
TABLE 1

Common Nuclear Imaging Techniques (15,75-77)

\begin{tabular}{|c|c|c|c|c|c|c|}
\hline Radiotracer & Target & $\begin{array}{l}\text { Main infectious } \\
\text { indications }\end{array}$ & Half-life & $\begin{array}{l}\text { Administered } \\
\text { activity (MBq) }\end{array}$ & Advantages & Disadvantages \\
\hline \multirow[t]{5}{*}{$\begin{array}{l}\text { Bone scan } \\
\quad(99 \mathrm{~m} T \mathrm{Tc}-\mathrm{MDP})\end{array}$} & $\begin{array}{r}\text { Active bone } \\
\text { formation }\end{array}$ & $\mathrm{PBI}^{\star}$ & $6 \mathrm{~h}$ & $500-1,110$ & Sensitive & Low specificity \\
\hline & & SOM & & & Low cost & $\begin{array}{l}\text { Susceptible to } \\
\text { confounders (surgery, } \\
\text { trauma) }\end{array}$ \\
\hline & & Late PJI & & & Accessible & \\
\hline & & Septic arthritis & & & $\begin{array}{c}\text { Good spatial } \\
\text { resolution }\end{array}$ & \\
\hline & & $\begin{array}{l}\text { Necrotizing external } \\
\text { otitis }\end{array}$ & & & Low radiation dose & \\
\hline \multirow[t]{6}{*}{$\begin{array}{l}\text { WBC scan } \\
\quad(99 \mathrm{~m} T c-W B C)\end{array}$} & Leukocytes & $\begin{array}{l}\mathrm{PBI}^{\dagger} \\
\quad \text { (violated bone) }\end{array}$ & $6 \mathrm{~h}$ & $185-370$ & $\begin{array}{l}\text { Sensitive, especially } \\
\text { for neutrophilic } \\
\text { induced } \\
\text { inflammation }\end{array}$ & $\begin{array}{l}\text { Depends on host immune } \\
\text { system; sensitivity } \\
\text { decreases after antibiotic } \\
\text { treatment }\end{array}$ \\
\hline & & Diabetic foot & & & & Blood exposure \\
\hline & & Early PJI & & & & Requires sterility \\
\hline & & $\begin{array}{l}\text { Infective } \\
\text { endocarditis }\end{array}$ & & & & Time consuming \\
\hline & & $\begin{array}{l}\text { Vascular graft } \\
\text { infection }\end{array}$ & & & & Poor resolution \\
\hline & & FUO & & & & High radiation dose \\
\hline \multirow[t]{5}{*}{${ }^{67} \mathrm{Ga}$-citrate } & Transferrin & SOM & $78.3 \mathrm{~h}$ & 150-220 & $\begin{array}{l}\text { Suitable for } \\
\text { immunodeficiency }\end{array}$ & Delayed imaging \\
\hline & $\begin{array}{l}\text { Bacterial } \\
\text { siderophores }\end{array}$ & $\begin{array}{l}\text { Opportunistic } \\
\text { infections }\end{array}$ & & & & Poor resolution \\
\hline & $\begin{array}{l}\text { Neutrophilic } \\
\text { lactoferrin }\end{array}$ & FUO & & & & High radiation dose \\
\hline & & $\begin{array}{l}\text { Necrotizing } \\
\text { external } \\
\text { otitis }\end{array}$ & & & & Expensive \\
\hline & & & & & & Requires cyclotron \\
\hline \multirow[t]{6}{*}{${ }^{18} \mathrm{~F}-\mathrm{FDG}$ PET } & $\begin{array}{l}\text { Energy } \\
\text { consumption }\end{array}$ & $\mathrm{PBI}^{\star}$ & $110 \mathrm{~min}$ & $185-740$ & Sensitive & $\begin{array}{l}\text { Depends on host } \\
\text { immune } \\
\text { system }\end{array}$ \\
\hline & & SOM & & & $\begin{array}{l}\text { Suitable for acute } \\
\text { and chronic } \\
\text { inflammation }\end{array}$ & Expensive \\
\hline & & $\begin{array}{l}\text { Infective } \\
\text { endocarditis }\end{array}$ & & & High resolution & $\begin{array}{l}\text { Lacks widespread } \\
\text { availability }\end{array}$ \\
\hline & & $\begin{array}{l}\text { Vascular graft } \\
\text { infection }\end{array}$ & & & $\begin{array}{l}\text { Relatively short } \\
\text { scan }\end{array}$ & $\begin{array}{l}\text { Susceptible to } \\
\text { confounders (e.g., surgery) }\end{array}$ \\
\hline & & FUO & & & SUV quantification & $\begin{array}{l}\text { Requires patient } \\
\text { preparation }\end{array}$ \\
\hline & & & & & & High radiation dose \\
\hline \multicolumn{7}{|c|}{$\begin{array}{l}{ }^{\dagger} \text { Violated bone. } \\
\text { MDP = methylene diphosphonate; } \mathrm{PBI}=\text { peripheral bone infection; SOM = spinal osteomyelitis; } \mathrm{PJI}=\text { prosthetic joint infection. }\end{array}$} \\
\hline
\end{tabular}

bone marrow can imitate normal hematopoiesis and therefore complicate the distinction of infected from reactive bone marrow. A possible solution is combining the WBC scan with an additional bone marrow scan. In this combined technique, an additional set of images with ${ }^{99 \mathrm{~m}} \mathrm{Tc}$-sulfur colloid is acquired to indicate normal marrow distribution, therefore improving the scan's specificity (26). 
${ }^{67} \mathrm{Ga}$-Citrate Scan. Although the ${ }^{67} \mathrm{Ga}$-citrate scan is used less frequently than in the past $(15,16,25)$, it remains a good choice for several conditions, especially for spinal osteomyelitis (25). It is used frequently when modalities such as MRI or ${ }^{18} \mathrm{~F}-\mathrm{FDG}$ PET/ $\mathrm{CT}$ are not available and is particularly sensitive when combined with bone scintigraphy $(4,13)$. Unlike the WBC scan, the ${ }^{67} \mathrm{Ga}-$ citrate scan does not require direct participation of immune cells, making it more suitable for immune-compromised patients (27). Gallium accumulates in sites of infection through several potential mechanisms. First, because of gallium's analogy to iron, it binds to transferrin and is recruited to inflammatory sites aided by increased vascular permeability and increased blood flow. Gallium may also bind to bacterial siderophores and activated lactoferrin in neutrophils and is partially absorbed by macrophages $(6,16,27)$.

${ }^{18} \mathrm{~F}$-FDG PET. Established first in oncology, PET is currently the dominant modality in NM $(15,17)$, with its most widely used radiotracer being ${ }^{18} \mathrm{~F}-\mathrm{FDG}$, a glucose analog that accumulates in cells with high metabolic rates such as tumors and active inflammatory cells. The increased glycolysis of inflammatory cells in different stages of the infection-neutrophils, macrophages, and lymphocytes $(17,18)$ - makes this technique suitable for acute as well as chronic disease, although not specific to the presence of bacteria themselves (17). Moreover, the favorable pharmacokinetic characteristics of ${ }^{18} \mathrm{~F}-\mathrm{FDG}$ allow perfusion in ischemic sites and promote imaging using a short postinjection delay of about $60 \mathrm{~min}(17,18)$. However, this exam is both expensive and not widely available (17), requiring the patient to adhere to a lowcarbohydrate diet as well as fast in the $6 \mathrm{~h}$ preceding the scan, avoid steroid treatment, regulate glucose levels, and abstain from high-impact sports $24 \mathrm{~h}$ before the examination (28). Differences in patient preparation therefore introduce considerable variability into the imaging outcome.

\section{CLINICAL USES OF NM IN IMAGING INFECTION}

Imaging is essential in the evaluation of deeper infections, that is, in the chest, abdomen or pelvis, or if the cause of infection is unknown. These scenarios frequently apply to sick inpatients, who are evaluated with a variety of structural and functional modalities including plain radiography, ultrasound, CT, and MRI. Frequently, structural imaging is enough to identify an abscess or other lesions. NM has an important and expanding role in 3 types of infection discussed here: musculoskeletal infection of joints, bone, and orthopedic hardware; cardiovascular infections, especially cardiac vegetations and infected prostheses; and infections whose source is not known, that is, fever of unknown origin (FUO).

\section{Musculoskeletal Infection-Osteomyelitis}

Osteomyelitis is an infection of bones and their surrounding structures, which is frequently caused by Staphylococcus aureus. Although this disease is typically disseminated hematogenously, it can also spread locally, especially in the setting of trauma or surgery $(9,18)$. Because the symptoms are nonspecific and might not include fever or pain, and because the physical examination and laboratory findings can vary, delayed diagnosis is common (29). In the setting of prosthetic joint infection, this delay can lead to devastating results requiring removal of the infected prosthesis as the only treatment (30). In a patient with persistent symptoms and no neurologic deficit, the workup will begin with plain radiography. Yet because of its low sensitivity and specificity, as well as late-appearing abnormalities, radiographs are used mostly to exclude other conditions (31). A more accurate tool is unenhanced
MRI, since it can identify tissue changes within $2 \mathrm{~d}$ of infection onset, can determine the involvement of bones and the surrounding tissues, and is sufficient for disease exclusion after only $1 \mathrm{wk}$ because of its high combined sensitivity and specificity and high negative predictive value $(18,31,32)$. In most cases of suspected osteomyelitis, NM techniques are applied as complementary methods (20) because of their high sensitivity. However, accurate diagnosis of osteomyelitis using existing tools is considered variable $(31,33)$.

Peripheral Bone Infection. For acute infection of nonviolated bones, TPBS, commonly enhanced by SPECT/CT, is recommended (9,31). This highly sensitive technique is an excellent tool for excluding infection, especially when disease probability is low (31). However, once a bone has undergone intervention (e.g., trauma, surgery, or placement of metallic hardware), the already low specificity of TPBS decreases even further because of the bone remodeling process, making WBC or bone marrow scanning the test of choice for these situations $(9,26,31) .{ }^{18} \mathrm{~F}-\mathrm{FDG}$ PET/CT is also less effective in violated bone and is currently recommended mostly when there is clinical suspicion of disseminated disease (31).

Spinal Osteomyelitis. In this entity, the ${ }^{67} \mathrm{Ga}$-citrate scan, frequently combined with a bone scan, can be a good alternative to MRI in spinal osteomyelitis, with sensitivity and specificity over $90 \%$ (4). However, ${ }^{18} \mathrm{~F}-\mathrm{FDG}$ PET/CT has shown superiority to ${ }^{67} \mathrm{Ga}$-citrate scanning and bone scintigraphy in diagnosing spinal osteomyelitis (34). Moreover, ${ }^{18} \mathrm{~F}-\mathrm{FDG}$ PET/CT has been shown to be superior to MRI for early ( $<2 \mathrm{wk}$ ) and low-grade infection and excellent for detecting chronic osteomyelitis, with $96 \%$ sensitivity regardless of the disease phase (35). However, it lacks the ability to differentiate infection from sterile inflammation (36). WBC scanning is not recommended for spinal osteomyelitis because of its low sensitivity and the overlap of the imaging findings of spinal osteomyelitis with other entities inciting marrow replacement $(4,9)$.

Prosthetic Joint Infection. For prosthetic joint infection, TPBS has frequently been used, with the bone remodeling process creating several limitations in the first 2 y after surgery. In this early stage, either WBC scanning or bone marrow scanning is recommended because of their high accuracy and ability to exclude the disease $(17,33)$. However, in a recent study of chronic prosthetic shoulder-joint infection, an extremely low sensitivity of $18 \%$ for WBC or bone marrow scanning was found, discouraging this recommendation (37). Figure 2 shows an example of WBC scanning for diagnosis of prosthetic joint infection in a 64 -y-old woman after knee replacement.

Although the role of ${ }^{18} \mathrm{~F}-\mathrm{FDG}$ PET/CT in prosthetic joint infection is not fully clear (17) ${ }^{18} \mathrm{~F}-\mathrm{FDG}-$ labeled leukocyte PET/CT showed promising results when used in patients with painful joint arthroplasty, suggesting that this method might be more specific than ${ }^{18} \mathrm{~F}$-FDG PET/CT alone (38).

\section{Cardiovascular System Infection}

NM, especially hybrid with structural imaging, has recently found a major role in diagnosing cardiovascular system infection. Although generally reserved for diagnostic failure of other imaging modalities or for evaluation of complications and treatment response, the use of NM in cardiovascular disease is expanding (39). In 2015, radiolabeled WBC SPECT/CT and ${ }^{18}$ F-FDG PET/CT imaging were added to the infective endocarditis guidelines of the European Society of Cardiology as supplementary methods to assist in the workup of possible infective endocarditis according to the Duke criteria in 


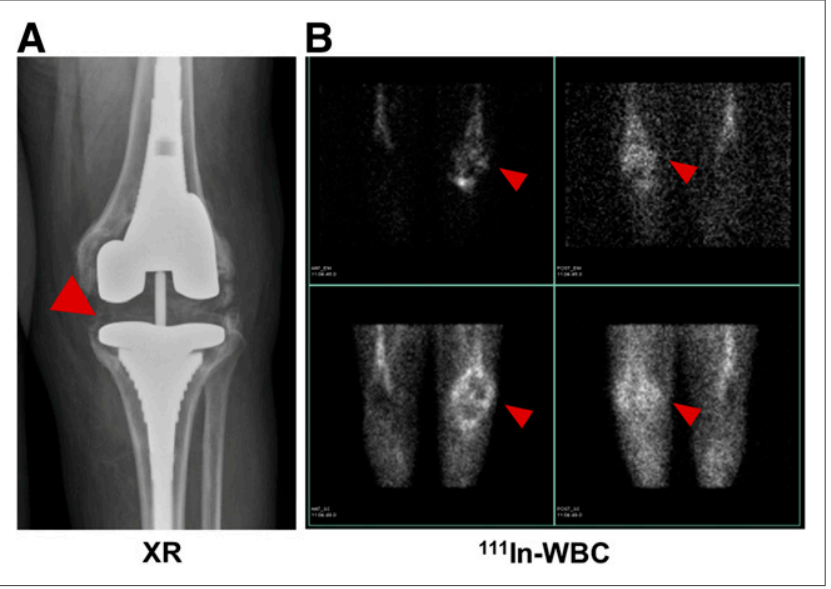

FIGURE 2. 64-y-old woman with knee replacement and periprosthetic osteomyelitis (red arrowhead) as depicted via plain radiography (A) and radiolabeled ${ }^{111} \mathrm{In}$-leukocyte imaging ( $\mathrm{B}$, top row) demonstrates brightest uptake at medial aspect of tibial plateau. ${ }^{99 \mathrm{mTC}} \mathrm{T}$-sulfur colloid imaging ( $\mathrm{B}$, bottom row) demonstrates no corresponding uptake in region of medial tibial plateau. Therefore, findings are consistent with osteomyelitis.

prosthetic valve endocarditis, as well as to detect extracardiac infectious foci and monitor treatment response (40). ${ }^{18} \mathrm{~F}-\mathrm{FDG}$ PET/CT was able to diagnose about $40 \%$ of patients with systemic emboli regardless of symptoms (39); however, its 5-mm-embolus threshold and its nonspecific tracer uptake in a postoperative setting may limit its use (40). In contrast, radiolabeled WBC SPECT/CT is a less sensitive yet more specific technique, even in postoperative settings (41). A combination of the 2 modalities has shown a nearly $100 \%$ specificity, highlighting the synergy of several imaging methods used in tandem $(40,42)$. Figure 3 shows an example of ${ }^{18} \mathrm{~F}-\mathrm{FDG}$ PET/CT in a 59-y-old patient with infective endocarditis.

Moreover, NM has been applied to less prevalent entities, such as vascular graft infection, in which $\mathrm{CT}$ angiography is commonly used. However, a recent metaanalysis showed WBC SPECT/CT to have a considerably higher pooled sensitivity and specificity than ${ }^{18}$ F-FDG PET/CT or CT angiography, suggesting that the former might be the most accurate modality for this entity (42).

\section{FUO}

Although FUO imaging workup usually begins with chest radiography and abdominal ultrasound (13), recent studies have shown the value of ${ }^{18} \mathrm{~F}-\mathrm{FDG}$ PET/CT imaging and advised its completion in an earlier stage of disease evaluation $(13,43)$. Historically, ${ }^{67} \mathrm{Ga}$-citrate was the NM modality of choice in FUO (24); however, its low sensitivity, specificity, and diagnostic yield have been suggested by a recent metaanalysis (44). Furthermore, a study that compared ${ }^{67} \mathrm{Ga}$-citrate SPECT/CT with ${ }^{18} \mathrm{~F}$-FDG PET/CT showed a higher sensitivity and clinical contribution for the latter (45).

Radiolabeled leukocytes are an alternative consideration. Although this method is considered accurate in patients for whom infection is strongly suspected, especially postoperatively (46), multiple studies that used leukocytes for FUO diagnosis showed low sensitivity and low diagnostic yield, especially when compared with ${ }^{18}$ F-FDG PET/CT $(13,44,47)$. Although these and other studies show the superiority of ${ }^{18} \mathrm{~F}$-FDG PET/CT in FUO diagnosis, ${ }^{67} \mathrm{Ga}$-citrate and WBC scans are likely to be performed if ${ }^{18} \mathrm{~F}$ FDG PET/CT is not available $(13,47)$. Highlighting the ability of

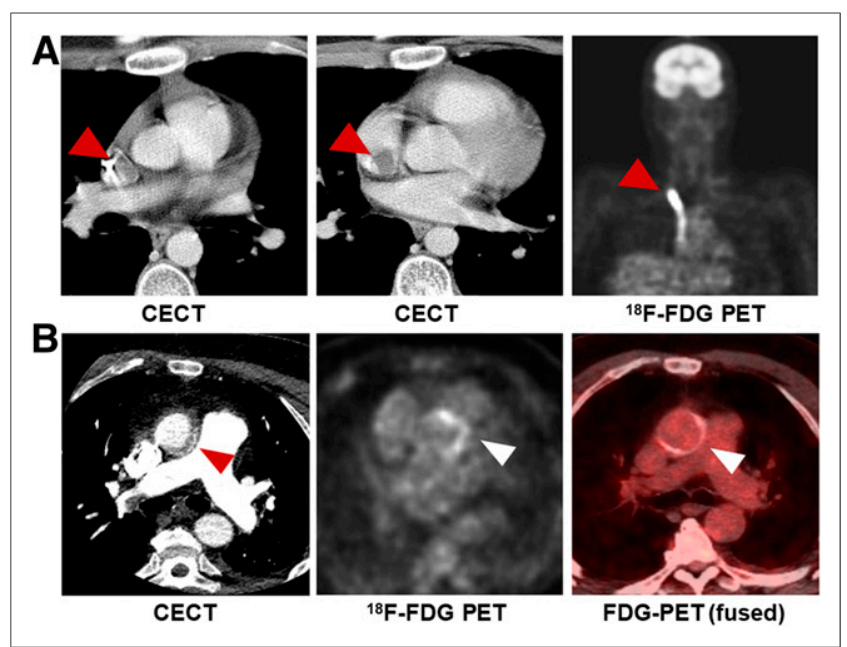

FIGURE 3. Examples of ${ }^{18} \mathrm{~F}-\mathrm{FDG}$ PET in cardiovascular disease. (A) A $17-y$-old boy with non-Hodgkin lymphoma, found to have catheter-associated thrombus consistent with infection, with arrowheads indicating increased FDG uptake in and around catheter. (B) A 59-y-old man with aortic valve prosthesis infection caused by $E$. faecalis, requiring surgical replacement. Arrowheads indicate increased uptake by valve. CECT = contrast-enhanced CT.

${ }^{18}$ F-FDG PET/CT to localize in occult infection, Figure 4 shows an incidental finding of tonsillar abscess in a patient being evaluated for metastatic cancer.

\section{NEWER APPROACHES TO MICROORGANISM-SPECIFIC IMAGING}

A growing body of literature describing PET and SPECT imaging of infection demonstrates the increasing interest in this field. In addition to the clinically used tracers described above, multiple new methods have been reported to differentiate infection from sterile inflammation. Several of these radiotracers have targeted unique microbial pathways, including bacteria-specific sugar transport, folic acid biosynthesis, iron accumulation, and cell wall components, especially peptidoglycan $(15,16,48)$. In this section, we will provide a brief review on small molecules $(<1,000 \mathrm{Da})$ reported as promising bacteria-sensitive PET tracers in the last decade (Table 2). This review excludes several innovative protein and peptide-based radiotracer methods, including radiolabeled antibodies.

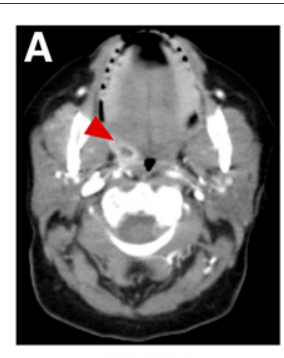

CECT

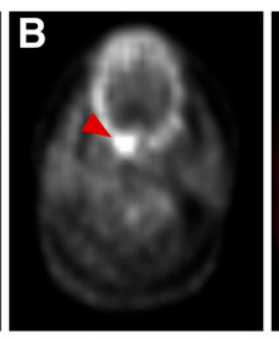

${ }^{18}$ F-FDG PET

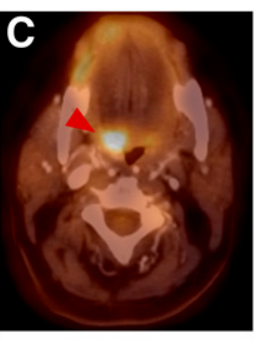

PET-CT (fused)
FIGURE 4. Incidental finding of infection in 65-y-old woman with fallopian tube cancer. (A) Contrast-enhanced CT shows tonsillar abscess (arrowheads). (B and C) Focal increase in uptake on ${ }^{18} \mathrm{~F}-\mathrm{FDG}$ PET and ${ }^{18} \mathrm{~F}-\mathrm{FDG} \mathrm{PET} / \mathrm{CT}$ in same location (red arrowhead). 
TABLE 2

Recent Bacteria-Specific Radiotracers

\begin{tabular}{|c|c|c|c|c|c|}
\hline Tracer & Mechanism & $\begin{array}{l}\text { Target bacterial } \\
\text { pathogen }\end{array}$ & $\begin{array}{l}\text { Pathogens tested } \\
\text { in vivo (CFUs } \\
\text { administered) }\end{array}$ & $\begin{array}{l}\text { Maximum infection-to- } \\
\text { inflammation ratio }\end{array}$ & $\begin{array}{l}\text { Stage } \\
\text { (published } \\
\text { reports) }\end{array}$ \\
\hline \multirow[t]{3}{*}{${ }^{18} \mathrm{~F}-\mathrm{FPTMP}$} & $\begin{array}{l}\text { Inhibition of bacterial } \\
\text { dihydrofolate reductase }\end{array}$ & $\mathrm{G}+, \mathrm{G}-$ & E. coli $\left(10^{6}-10^{8}\right)$ & $\sim 3\left(10^{8}\right.$ E. coli CFU) & Preclinical \\
\hline & & & S. aureus $\left(10^{8}\right)$ & & \\
\hline & & & P. aeruginosa $\left(10^{7}\right)$ & & \\
\hline${ }^{18} \mathrm{~F}-\mathrm{FAG}$ & Bacterial cell wall & $\mathrm{G}+, \mathrm{G}-$ & E. coli $\left(10^{7}\right)$ & $\sim 2$ & Preclinical \\
\hline${ }^{18} \mathrm{~F}$-maltohexaose & Maltodextrin transporter & $\mathrm{G}+, \mathrm{G}-$ & E. coli $\left(10^{5}-10^{9}\right)$ & 7 (109 CFU) & Preclinical \\
\hline${ }^{18} \mathrm{~F}$-fluoro-maltose & Maltodextrin transporter & $\mathrm{G}+, \mathrm{G}-$ & E. coli $\left(10^{8}\right)$ & 1.3 & Preclinical \\
\hline \multirow{4}{*}{$\begin{array}{l}{ }^{18} \mathrm{~F} \text {-fluoro- } \\
\text { maltotriose }\end{array}$} & Maltodextrin transporter & $\mathrm{G}+, \mathrm{G}-$ & E. coli $\left(10^{6}-10^{8}\right)$ & $3.4\left(10^{8}\right.$ E. coli CFU) & Preclinical \\
\hline & & & L. monocytogenes $\left(2 \times 10^{5}\right)$ & & \\
\hline & & & $P$. aeruginosa $\left(10^{6}\right)$ & & \\
\hline & & & S. aureus & & \\
\hline \multirow[t]{3}{*}{${ }^{18} \mathrm{~F}-\mathrm{FDS}$} & $\begin{array}{l}\text { Bacterial energy } \\
\text { consumption }\end{array}$ & $\mathrm{G}^{*}$ & E. coli $\left(10^{7}\right)$ & 7.3 (E. coli) & Clinical \\
\hline & & & S. aureus $\left(10^{7}-10^{8}\right)$ & & \\
\hline & & & P. aeruginosa $\left(10^{6.5}\right)$ & & \\
\hline${ }^{11} \mathrm{C}-\mathrm{PABA}$ & Folic acid biosynthesis & $\mathrm{G}+, \mathrm{G}-$ & E. coli & 2.6 & Clinical \\
\hline${ }^{18} \mathrm{~F}-\mathrm{PABA}$ & Folic acid biosynthesis & $\mathrm{G}+, \mathrm{G}-$ & S. aureus $\left(10^{7}-10^{8}\right)$ & $7.95\left(10^{8}\right)$ & Preclinical \\
\hline \multirow[t]{2}{*}{${ }^{11} \mathrm{C}-\mathrm{D}-\mathrm{Met}$} & Bacterial cell wall & $\mathrm{G}+, \mathrm{G}-$ & E. coli & 2 & Clinical \\
\hline & & & S. aureus & & \\
\hline \multirow[t]{3}{*}{${ }^{11} \mathrm{C}$-D-Ala } & Bacterial cell wall & $\mathrm{G}+, \mathrm{G}-$ & E. coli $\left(5 \times 10^{6}\right)$ & 3.5 (S. aureus) & Preclinical \\
\hline & & & S. aureus $\left(5 \times 10^{6}\right)$ & & \\
\hline & & & P. aeruginosa $\left(2 \times 10^{6}\right)$ & & \\
\hline
\end{tabular}

*Enterobacteriaceae.

$\mathrm{CFU}=$ colony forming units; ${ }^{18} \mathrm{~F}-\mathrm{FPTMP}={ }^{18} \mathrm{~F}$-fluoropropyl-trimethoprim; $\mathrm{G}+=$ Gram-positive bacteria; G- $=\mathrm{Gram}$-negative bacteria; ${ }^{18} \mathrm{~F}-\mathrm{FAG}=2$-deoxy-2- ${ }^{18} \mathrm{~F}$-fluoroacetamido-D-glucopyranose; ${ }^{18} \mathrm{~F}$-FDS $=2$-deoxy-2- ${ }^{18} \mathrm{~F}$-fluorosorbitol; ${ }^{11} \mathrm{C}$-D-Met $=\mathrm{D}-\mathrm{methyl}$ - ${ }^{11} \mathrm{C}$ methionine.

\section{Antibiotics}

Many antibiotic and antifungal agents have been investigated as bacteria-specific diagnostic radiotracers, with ciprofloxacin being the most thoroughly studied. Although initially considered promising, ${ }^{99 m}$ Tc-ciprofloxacin showed inconsistent and unsatisfying results in several clinical trials, suggesting low specificity for bacterial infection $(49,50)$. A recent study speculated that this low performance might be related to the increase in drug-resistant bacteria (51). A more promising study was published recently by Sellmyer et al., who reported on the PET analog bacterial dihydrofolate reductase inhibitor ${ }^{18} \mathrm{~F}$-fluoropropyl-trimethoprim and showed that it could differentiate between infection, chemical inflammation, and tumors in rodent models (Fig. 5A) (52). Demonstrating its clinical promise, a dosimetry study of ${ }^{11} \mathrm{C}$-trimethoprim was performed and showed that the absorbed radiation doses were well within safe limits for patients (53). Currently, this tracer is being evaluated further in clinical trials. Other fluoroquinolones, cephalosporins, and several antituberculosis drugs have not yielded satisfactory imaging data $(16,48,54)$.

\section{Carbohydrates}

One of the first carbohydrates to be explored as an infection-specific radiotracer was 2-deoxy-2- ${ }^{18} \mathrm{~F}$-fluoroacetamido-D-glucopyranose, a glucosamine analog, which could identify Escherichia coli infection in rats with an approximately 2 -fold calculated accumulation of the tracer in infected versus inflamed tissue (55). The bacterial universal hexose phosphate transporter has also been targeted. Mills et al. phosphorylated ${ }^{18} \mathrm{~F}-\mathrm{FDG}$ to produce 2deoxy-2- ${ }^{18}$ F-fluoro-D-glucose-6-phosphate, a substrate for this transporter, with promising in vitro results. However, although the tracer could differentiate infection from sterile inflammation in mice, the lower signal and similar biodistribution to ${ }^{18} \mathrm{~F}-\mathrm{FDG}$ raised concerns about its clinical utility (56).

Several groups have targeted the maltodextrin transporter, a well-known system responsible for carbohydrate uptake in bacterial cells. ${ }^{18} \mathrm{~F}$-maltohexaose has shown promising preliminary results in rats infected with $E$. coli when used to differentiate live from dead bacteria in the early stages of the bacterial infection (Fig. 6A). It was both more sensitive and more specific than ${ }^{18} \mathrm{~F}-$ FDG, showing a 7-fold increase in tracer accumulation in infected tissue compared with the sterile control, and sensitivity to drugresistant bacteria (57). A similar approach was taken by Gowrishankar et al. using ${ }^{18} \mathrm{~F}$-fluoromaltose. This tracer showed an approximately 1.3-fold increase in tracer uptake in infection versus sterile inflammation and high background noise (58). Later, ${ }^{18} \mathrm{~F}$-fluoromaltotriose, 


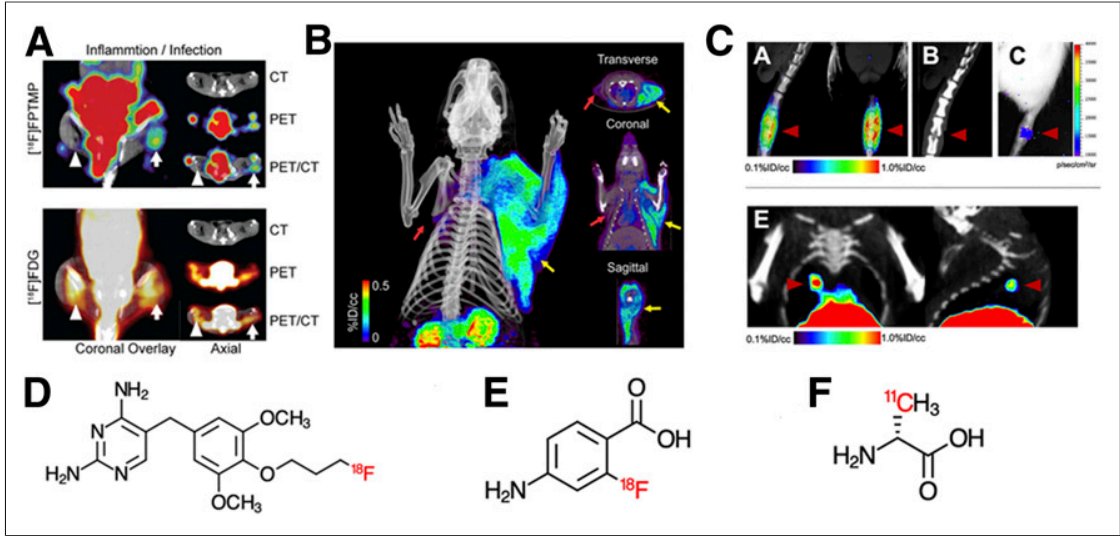

FIGURE 5. Examples of novel non-sugar-based infection-targeted radiotracers for PET. (A and B) Increased uptake of radiotracers in infection compared with sterile inflammation in 2 rodent models: ${ }^{18} \mathrm{~F}$-fluoropropyl-trimethoprim (FPTMP) uptake in mice infected with E. coli (arrowhead shows sterile inflammation, arrow shows infection) (A, reprinted with permission of (53)) and ${ }^{18} \mathrm{~F}$ PABA uptake in rat infected with $S$. aureus (red arrows show sterile inflammation, yellow arrows show infection) (B, reprinted with permission of (64)). (C) ${ }^{11} \mathrm{C}$-D-Ala uptake in rat intervertebral disk infected with $S$. aureus (red arrowheads) and mouse lung infected with $P$. aeruginosa (red arrowheads). (Reprinted with permission of (73).) (D-F) Chemical structures of ${ }^{18} \mathrm{~F}-\mathrm{FPTMP}$ (D), ${ }^{18} \mathrm{~F}-$ PABA $(E)$, and ${ }^{11} \mathrm{C}-\mathrm{D}-\mathrm{Ala}(\mathrm{F}) . \mathrm{ID}=$ injected dose.

a second-generation tracer produced by the same group, showed better results, accumulating in both E. coli and Pseudomonas aeruginosa, with a 3.4-fold higher tracer uptake in $E$. coli-infected tissue than in sterile controls and an improved signal-to-noise ratio (Fig. 6B) (59).

2-deoxy-2- ${ }^{18}$ F-fluorosorbitol, a fluorinated sorbitol analog, was first reported in 2008 as a potential cancer biomarker by Li et al. (60). This sugar alcohol is formed by a trivial chemical reduction of ${ }^{18} \mathrm{~F}-\mathrm{FDG}$. The metabolism of this sugar in gram-negative bacteria was the premise of the 2014 Weinstein et al. study that showed a 7-fold increased uptake of 2-deoxy-2- ${ }^{18}$ F-fluorosorbitol

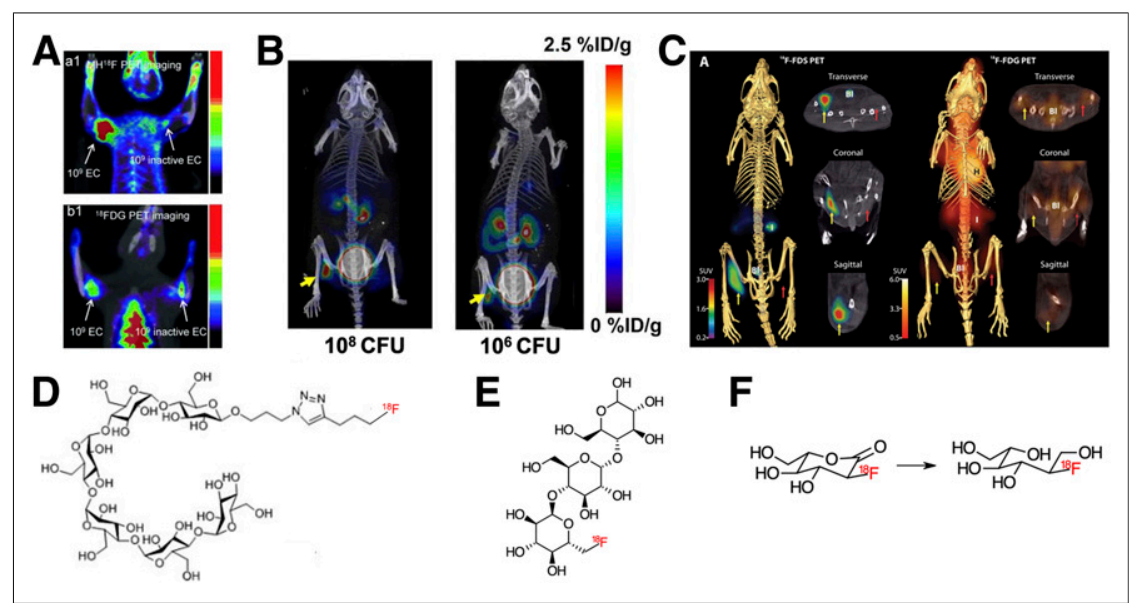

FIGURE 6. Examples of novel sugar-based infection-targeted radiotracers for PET/CT. (A-C) Increased uptake of radiotracers in infection compared with sterile inflammation in 3 rodent models: ${ }^{18} \mathrm{~F}$-maltohexaose uptake in rat infected with $E$. coli (left arrows show infection, right arrows show sterile inflammation) (A, reprinted with permission of $(57)),{ }^{18} \mathrm{~F}$-fluoromaltotriose uptake in mice infected with $E$. coli (yellow arrow shows infection site) $(B$, reprinted with permission of (59)), and 2-deoxy-2-18 F-fluorosorbitol ( $\left.{ }^{18} \mathrm{~F}-\mathrm{FDS}\right)$ uptake in mice infected with $E$. coli (yellow arrows show infection, red arrows show sterile inflammation). (C, reprinted with permission of (61)). (D-F) Chemical structures of ${ }^{18} \mathrm{~F}$-maltohexaose (D), ${ }^{18} \mathrm{~F}$-fluoromaltotriose (E), and ${ }^{18} \mathrm{~F}-\mathrm{FDS}(\mathrm{F})$, obtained from chemical reduction of ${ }^{18} \mathrm{~F}-\mathrm{FDG}$. $\mathrm{CFU}=$ colony-forming unit; ID = injected dose. in tissues infected with Enterobacteriaceae compared to sterile inflammation in both immunocompetent and immunodeficient mice (Fig. 6C) (61). Furthermore, the tracer showed dramatically decreased signal in mice infected with drug-susceptible and drug-resistant $E$. coli when they were treated with ceftriaxone. These results suggest that 2 -deoxy-2- ${ }^{18}$ F-fluorosorbitol might not only help monitor antimicrobial therapy but also identify resistant bacteria, allowing more accurate therapy in patients (61). Subsequently, several clinical trials have demonstrated the safety of 2deoxy-2- ${ }^{18}$ F-fluorosorbitol in healthy human volunteers (62), as well as favorable renal kinetics (63).

\section{Cofactor or DNA Synthesis}

The folate biosynthesis pathway has been targeted in antibiotic therapy, most notably with trimethoprim or sulfamethoxazole therapy (inhibiting dihydrofolate reductase and dihydropteroate reductase, respectively). Paraaminobenzoic acid (PABA) is a precursor of folic acid in bacteria but not in mammalian cells, and its radiolabeled versions were studied both as ${ }^{11} \mathrm{C}$-PABA (8) and as ${ }^{18} \mathrm{~F}$-PABA (64). PABA showed incorporation in both grampositive and gram-negative bacteria and the ability to identify infected tissue, with an infection-to-inflammation ratio of 2.6 for ${ }^{11} \mathrm{C}$-PABA and 7.95 for ${ }^{18} \mathrm{~F}-\mathrm{PABA}$ in $E$. coli and $S$. aureus infection (Fig. 5B), respectively. Interestingly, when an unlabeled the solution containing ${ }^{18} \mathrm{~F}-\mathrm{PABA}$, as a means to saturate the metabolic processes requiring it, the tracer uptake greatly increased, raising the infection-to-inflammation ratio to as high as $9.38 \pm 2.43$. Furthermore, reduced uptake of ${ }^{18} \mathrm{~F}$-PABA in infected tissue treated with antibiotics was reported. This finding can potentially play a role in the identification of treatment response in the future (64). These folate precursors are closely related to the antibiotic-derived PET tracer targeting folate biosynthesis ${ }^{18}$ F-fluoropropyl-trimethoprim.

A radiotracer strategy more explicitly targeting bacterial DNA synthesis uses the nucleoside analog ${ }^{124} \mathrm{I}$-FIAU, which is phosphorylated by thymidine kinases and subsequently trapped inside bacterial cells (16). Although promising in animal studies (16), this tracer showed inconclusive results in clinical trials. Even though ${ }^{124} \mathrm{I}$ FIAU managed to diagnose musculoskeletal infection in a small group of patients, it later failed to do so when evaluating 22 patients with prosthetic joint infection and showed low specificity and poor image quality (65).

\section{Iron Transport and Storage}

Although ${ }^{67} \mathrm{Ga}$-citrate is a well-known and established SPECT radiotracer, its role 
in nuclear imaging has been decreasing. However, iron metabolism remains a focus in nuclear imaging research, with gallium (III) widely considered a surrogate for Fe (III). ${ }^{68} \mathrm{Ga}$-citrate, a PET tracer with a 68-min half-life, allows for same-day imaging and produces a higher image quality than its ${ }^{67} \mathrm{Ga}$ counterpart $(66,67)$. Nevertheless, its diagnostic value has been controversial. Although it has demonstrated high sensitivity in the diagnosis of diskitis and osteomyelitis (68), distinguished septic from aseptic inflammation in prosthetic joints (69), and differentiated active from inactive tuberculosis lesions (70), it failed to demonstrate an advantage over known modalities, such as labeled leukocytes and ${ }^{18} \mathrm{~F}-\mathrm{FDG}$ PET, in animal models. Moreover, it showed inferiority to ${ }^{67} \mathrm{Ga}$-citrate in 60 patients with suspected bone or joint infection or FUO (67).

Siderophores, secreted iron chelators that are commonly used by both bacteria and fungi (48), have been extensively studied for bacteria- and fungus-specific detection. Petrik et al. have published several studies showing the potential of pathogen-specific siderophores for imaging studies. ${ }^{68} \mathrm{Ga}$-triacetylfusarinine $\mathrm{C}$ and ${ }^{68} \mathrm{Ga}$-ferrioxamine $\mathrm{E}$ were shown to be an effective tool for fungi imaging both in vitro and in vivo (71) and later, ${ }^{68} \mathrm{Ga}$-pyoverdine-PAO1, a siderophore produced by $P$. aeruginosa, was shown to have an increased uptake in Pseudomonas-infected lung, showing an improved distribution compared with ${ }^{18} \mathrm{~F}$-FDG and ${ }^{68} \mathrm{Ga}$-citrate in animal models (72).

\section{D-Amino Acids}

Another approach targeting bacteria-specific structures uses substrates for the bacterial cell wall, in particular peptidoglycan. Since mammalian cells generally use L-amino acids as metabolic substrates, D-amino acids are thought to be more specific to bacterial metabolism. Moreover, the fast incorporation of D-amino acids into bacterial peptidoglycan in both gram-positive and gram-negative bacteria provides an appealing target for infection imaging. Neumann et al. showed a rapid accumulation of D-methyl- ${ }^{11} \mathrm{C}-$ methionine in mice infected with $E$. coli and $S$. aureus without accumulation in the control sterile inflammation (36). Moreover, a recently published paper by Parker et al. showed a 3.5-fold higher accumulation of ${ }^{11} \mathrm{C}$-D-ala in a mouse model of acute bacterial myositis compared with the sterile inflammation control, whereas ${ }^{68} \mathrm{Ga}$-citrate showed only 2-fold higher accumulation in the same model. Furthermore, in a vertebral diskitis-osteomyelitis modal, ${ }^{11} \mathrm{C}$-D-ala showed a 3.3-fold higher uptake than in adjacent disk spaces and a 1.8 -fold uptake in $P$. aeruginosa pneumonia relative to normal lung (Figure 5C) (73).

\section{CONCLUSION}

The limitations of current nuclear imaging methods to detect bacterial infection have motivated numerous new approaches targeting bacteriaspecific proteins and metabolic pathways. Although the radiotracers studied are relatively unproven, success in this area may revolutionize the management of infectious diseases in clinical practice.

\section{REFERENCES}

1. Blair JMA, Webber MA, Baylay AJ, Ogbolu DO, Piddock LJV. Molecular mechanisms of antibiotic resistance. Nat Rev Microbiol. 2015;13:42-51.

2. Lloyd DH. Alternatives to conventional antimicrobial drugs: a review of future prospects. Vet Dermatol. 2012;23:299-304.

3. Meyer M, Testart N, Jreige M, et al. Diagnostic performance of PET or PET/CT using ${ }^{18} \mathrm{~F}$-FDG labeled white blood cells in infectious diseases: a systematic review and a bivariate meta-analysis. Diagnostics (Basel). 2019;9:60.

4. Berbari EF, Kanj SS, Kowalski TJ, et al. 2015 Infectious Diseases Society of America (IDSA) clinical practice guidelines for the diagnosis and treatment of native vertebral osteomyelitis in adults. Clin Infect Dis. 2015;61:e26-e46.
5. Tingström P, Milberg A, Sund-Levander M. Early nonspecific signs and symptoms of infection in institutionalized elderly persons: perceptions of nursing assistants. Scand J Caring Sci. 2010;24:24-31.

6. Xu T, Chen Y. Research progress of $\left[{ }^{68} \mathrm{Ga}\right]$ citrate PET's utility in infection and inflammation imaging: a review. Mol Imaging Biol. 2020;22:22-32.

7. Pober JS, Sessa WC. Inflammation and the blood microvascular system. Cold Spring Harb Perspect Biol. 2014;7:a016345.

8. Mutch CA, Ordonez AA, Qin H, et al. $\left[{ }^{11} \mathrm{C}\right]$ Para-aminobenzoic acid: a positron emission tomography tracer targeting bacteria-specific metabolism. ACS Infect Dis. 2018;4:1067-1072.

9. Lee YJ, Sadigh S, Mankad K, Kapse N, Rajeswaran G. The imaging of osteomyelitis. Quant Imaging Med Surg. 2016;6:184-198.

10. Khalil MM, Tremoleda JL, Bayomy TB, Gsell W. Molecular SPECT imaging: an overview. Int J Mol Imaging. 2011;2011:796025.

11. Cortellaro F, Ferrari L, Molteni F, et al. Accuracy of point of care ultrasound to identify the source of infection in septic patients: a prospective study. Intern Emerg Med. 2017;12:371-378.

12. Kumar R, Basu S, Torigian D, Anand V, Zhuang H, Alavi A. Role of modern imaging techniques for diagnosis of infection in the era of ${ }^{18} \mathrm{~F}$-fluorodeoxyglucose positron emission tomography. Clin Microbiol Rev. 2008;21:209-224.

13. Mulders-Manders C, Simon A, Bleeker-Rovers C. Fever of unknown origin. Clin Med (Lond). 2015;15:280-284.

14. Berger A. Magnetic resonance imaging. BMJ. 2002;324:35.

15. Sethi I, Baum YS, Grady EE. Current status of molecular imaging of infection: a primer. AJR. 2019;213:300-308.

16. Ordonez AA, Jain SK. Pathogen-specific bacterial imaging in nuclear medicine. Semin Nucl Med. 2018;48:182-194.

17. Vaidyanathan S, Patel CN, Scarsbrook AF, Chowdhury FU. FDG PET/CT in infection and inflammation: current and emerging clinical applications. Clin Radiol. 2015;70:787-800.

18. Palestro CJ. Radionuclide imaging of musculoskeletal infection: a review. J Nucl Med. 2016;57:1406-1412.

19. Dinh T, McWhorter N. Triple phase bone scan. StatPearls website. https:// www.statpearls.com/as/musculoskeletal/30618/. Updated August 27, 2020. Accessed September 23, 2020.

20. Van den Wyngaert T, Strobel K, Kampen WU, et al. The EANM practice guidelines for bone scintigraphy. Eur J Nucl Med Mol Imaging. 2016;43:1723-1738.

21. Adams C, Banks KP. Bone scan. StatPearls website. https://www.statpearls.com/ as/musculoskeletal/18454/. Updated September 2, 2020. Accessed September 23, 2020.

22. Roca M, de Vries EFJ, Jamar F, Israel O, Signore A. Guidelines for the labelling of leucocytes with ${ }^{111}$ In-oxine: Inflammation/Infection Taskgroup of the European Association of Nuclear Medicine. Eur J Nucl Med Mol Imaging. 2010;37: 835-841.

23. Auletta S, Riolo D, Varani M, Lauri C, Galli F, Signore A. Labelling and clinical performance of human leukocytes labelled with ${ }^{99 \mathrm{~m}} \mathrm{Tc}-\mathrm{HMPAO}$ using Leukokit ${ }^{\circledR}$ with Gelofusine versus Leukokit ${ }^{\circledR}$ with HES as sedimentation agent. Contrast Media Mol Imaging. 2019;2019:4368342.

24. Censullo A, Vijayan T. Using nuclear medicine imaging wisely in diagnosing infectious diseases. Open Forum Infect Dis. 2017;4:ofx011.

25. Palestro CJ. Radionuclide imaging of osteomyelitis. Semin Nucl Med. 2015;45: 32-46.

26. Palestro CJ, Love C, Tronco GG, Tomas MB, Rini JN. Combined labeled leukocyte and technetium $99 \mathrm{~m}$ sulfur colloid bone marrow imaging for diagnosing musculoskeletal infection. Radiographics. 2006;26:859-870.

27. Palestro CJ. The current role of gallium imaging in infection. Semin Nucl Med. 1994;24:128-141.

28. Lankinen P, Noponen T, Autio A, et al. A comparative ${ }^{68} \mathrm{Ga}$-citrate and ${ }^{68} \mathrm{Ga}-$ chloride PET/CT imaging of Staphylococcus aureus osteomyelitis in the rat tibia. Contrast Media Mol Imaging. 2018;2018:9892604.

29. Zimmerli W. Clinical practice: vertebral osteomyelitis. N Engl J Med. 2010;362: 1022-1029.

30. Tande AJ, Patel R. Prosthetic joint infection. Clin Microbiol Rev. 2014;27: 302-345.

31. Glaudemans AWJM, Jutte PC, Cataldo MA, et al. Consensus document for the diagnosis of peripheral bone infection in adults: a joint paper by the EANM, EBJIS, and ESR (with ESCMID endorsement). Eur J Nucl Med Mol Imaging. 2019;46:957-970.

32. Momodu I, Savaliya V. Osteomyelitis. StatPearls website. https://www.statpearls.com/as/musculoskeletal/26397/. Updated August 10, 2020. Accessed September 23, 2020.

33. Signore A, Sconfienza LM, Borens O, et al. Consensus document for the diagnosis of prosthetic joint infections: a joint paper by the EANM, EBJIS, and ESR (with ESCMID endorsement). Eur J Nucl Med Mol Imaging. 2019; 46:971-988. 
34. Fuster $\mathrm{D}$, Solà $\mathrm{O}$, Soriano $\mathrm{A}$, et al. A prospective study comparing whole-body FDG PET/CT to combined planar bone scan with ${ }^{67} \mathrm{Ga}$ SPECT/CT in the diagnosis of spondylodiskitis. Clin Nucl Med. 2012;37:827-832.

35. Smids C, Kouijzer IJE, Vos FJ, et al. A comparison of the diagnostic value of MRI and ${ }^{18}$ F-FDG-PET/CT in suspected spondylodiscitis. Infection. 2017;45:41-49.

36. Neumann KD, Villanueva-Meyer JE, Mutch CA, et al. Imaging active infection in vivo using d-amino acid derived PET radiotracers. Sci Rep. 2017;7:7903.

37. Falstie-Jensen T, Daugaard H, Soballe K, Ovesen J, Arveschoug AK, Lange J. Labeled white blood cell/bone marrow single-photon emission computed tomography with computed tomography fails in diagnosing chronic periprosthetic shoulder joint infection. J Shoulder Elbow Surg. 2019;28:1040-1048.

38. Aksoy SY, Asa S, Ozhan M, et al. FDG and FDG-labelled leucocyte PET/CT in the imaging of prosthetic joint infection. Eur J Nucl Med Mol Imaging. 2014;41:556-564.

39. Habib G, Erba PA, Iung B, et al. Clinical presentation, aetiology and outcome of infective endocarditis: results of the ESC-EORP EURO-ENDO (European infective endocarditis) registry: a prospective cohort study. Eur Heart J. 2019;40:3222-3232.

40. Habib G, Lancellotti P, Antunes MJ, et al. 2015 ESC guidelines for the management of infective endocarditis: the task force for the management of infective endocarditis of the European Society of Cardiology (ESC). Eur Heart J. 2015;36:3075-3128.

41. Rouzet F, Chequer R, Benali K, et al. Respective performance of ${ }^{18} \mathrm{~F}$-FDG PET and radiolabeled leukocyte scintigraphy for the diagnosis of prosthetic valve endocarditis. J Nucl Med. 2014;55:1980-1985.

42. Reinders Folmer EI, Von Meijenfeldt GCI, Van der Laan MJ, et al. Diagnostic imaging in vascular graft infection: a systematic review and meta-analysis. Eur J Vasc Endovasc Surg. 2018;56:719-729.

43. Kouijzer IJE, Mulders-Manders CM, Bleeker-Rovers CP, Oyen WJG. Fever of unknown origin: the value of FDG-PET/CT. Semin Nucl Med. 2018;48:100-107.

44. Takeuchi M, Dahabreh IJ, Nihashi T, Iwata M, Varghese GM, Terasawa T. Nuclear imaging for classic fever of unknown origin: meta-analysis. J Nucl Med. 2016;57:1913-1919.

45. Hung B-T, Wang P-W, Su Y-J, et al. The efficacy of ${ }^{18} \mathrm{~F}-\mathrm{FDG}$ PET/CT and ${ }^{67} \mathrm{Ga}$ SPECT/CT in diagnosing fever of unknown origin. Int J Infect Dis. 2017;62:10-17.

46. Signore A, Jamar F, Israel O, Buscombe J, Martin-Comin J, Lazzeri E. Clinical indications, image acquisition and data interpretation for white blood cells and anti-granulocyte monoclonal antibody scintigraphy: an EANM procedural guideline. Eur J Nucl Med Mol Imaging. 2018;45:1816-1831.

47. Dibble EH, Yoo DC, Baird GL, Noto RB. FDG PET/CT of infection: should it replace labeled leukocyte scintigraphy of inpatients? AJR. 2019;213:1358-1365.

48. Welling MM, Hensbergen AW, Bunschoten A, Velders AH, Roestenberg M, van Leeuwen FWB. An update on radiotracer development for molecular imaging of bacterial infections. Clin Transl Imaging. 2019;7:105-124.

49. Sarda L, Crémieux A-C, Lebellec Y, et al. Inability of ${ }^{99 \mathrm{~m}} \mathrm{Tc}$-ciprofloxacin scintigraphy to discriminate between septic and sterile osteoarticular diseases. $\mathrm{J} \mathrm{Nucl}$ Med. 2003;44:920-926.

50. Dumarey N, Blocklet D, Appelboom T, Tant L, Schoutens A. Infecton is not specific for bacterial osteo-articular infective pathology. Eur J Nucl Med Mol Imaging. 2002;29:530-535.

51. Naqvi SAR, Roohi S, Sabir H, Shahzad SA, Aziz A, Rasheed R. Susceptibility of ${ }^{99 m}$ Tc-ciprofloxacin for common infection causing bacterial strains isolated from clinical samples: an in vitro and in vivo study. Appl Biochem Biotechnol. 2019;188:424-435.

52. Sellmyer MA, Lee I, Hou C, et al. Bacterial infection imaging with $\left[{ }^{18} \mathrm{~F}\right]$ fluoropropyl-trimethoprim. Proc Natl Acad Sci USA. 2017;114:8372-8377.

53. Doot R, Young A, Schubert E, et al. First-in-human biodistribution and dosimetry of $\left[{ }^{11} \mathrm{C}\right]$ trimethoprim [abstract]. J Nucl Med. 2019;60(suppl):1642.

54. Zhang Z, Ordonez AA, Smith-Jones P, et al. The biodistribution of 5-[ $\left[{ }^{18} \mathrm{~F}\right]$ fluoropyrazinamide in Mycobacterium tuberculosis-infected mice determined by positron emission tomography. PLoS One. 2017;12:e170871.
55. Martínez ME, Kiyono Y, Noriki S, et al. New radiosynthesis of 2-deoxy-2-[ $\left[{ }^{18} \mathrm{~F}\right]$ fluoroacetamido-D-glucopyranose and its evaluation as a bacterial infections imaging agent. Nucl Med Biol. 2011;38:807-817.

56. Mills B, Awais RO, Luckett J, et al. $\left[\left({ }^{18} \mathrm{~F}\right)\right]$ FDG-6-P as a novel in vivo tool for imaging staphylococcal infections. EJNMMI Res. 2015;5:13.

57. Ning $X$, Seo W, Lee S, et al. PET imaging of bacterial infections with fluorine18-labeled maltohexaose. Angew Chem Int Ed Engl. 2014;53:14096-14101.

58. Gowrishankar G, Namavari M, Jouannot EB, et al. Investigation of 6-[ $\left.{ }^{18} \mathrm{~F}\right]-$ fluoromaltose as a novel PET tracer for imaging bacterial infection. PLoS One. 2014;9:e107951.

59. Gowrishankar G, Hardy J, Wardak M, et al. Specific imaging of bacterial infection using $6 "{ }^{\prime \prime}{ }^{18} \mathrm{~F}$-fluoromaltotriose: a second-generation PET tracer targeting the maltodextrin transporter in bacteria. J Nucl Med. 2017;58:1679-1684.

60. Li Z-B, Wu Z, Cao Q, et al. The synthesis of ${ }^{18} \mathrm{~F}-\mathrm{FDS}$ and its potential application in molecular imaging. Mol Imaging Biol. 2008;10:92-98.

61. Weinstein EA, Ordonez AA, DeMarco VP, et al. Imaging Enterobacteriaceae infection in vivo with ${ }^{18} \mathrm{~F}$-fluorodeoxysorbitol positron emission tomography. Sci Transl Med. 2014;6:259ra146.

62. Zhu W, Yao S, Xing H, et al. Biodistribution and radiation dosimetry of the Enterobacteriaceae-specific imaging probe $\left[{ }^{18} \mathrm{~F}\right]$ fluorodeoxysorbitol determined by PET/CT in healthy human volunteers. Mol Imaging Biol. 2016;18:782-787.

63. Werner RA, Ordonez AA, Sanchez-Bautista J, et al. Novel functional renal PET imaging with ${ }^{18}$ F-FDS in human subjects. Clin Nucl Med. 2019;44:410-411.

64. Zhang Z, Ordonez AA, Wang H, et al. Positron emission tomography imaging with 2-[ $\left.{ }^{18} \mathrm{~F}\right] \mathrm{F}$-p-aminobenzoic acid detects staphylococcus aureus infections and monitors drug response. ACS Infect Dis. 2018;4:1635-1644.

65. Zhang XM, Zhang HH, McLeroth P, et al. [ $\left.{ }^{124} \mathrm{I}\right]$ FIAU: human dosimetry and infection imaging in patients with suspected prosthetic joint infection. Nucl Med Biol. 2016;43:273-279.

66. Morgat C, Hindié E, Mishra AK, Allard M, Fernandez P. Gallium-68: chemistry and radiolabeled peptides exploring different oncogenic pathways. Cancer Biother Radiopharm. 2013;28:85-97.

67. Segard T, Morandeau LMJA, Dunne ML, et al. Comparison between gallium-68 citrate PET-CT and gallium-67 citrate scintigraphy for infection imaging. Intern Med J. 2019;49:1016-1022.

68. Nanni C, Errani C, Boriani L, et al. ${ }^{68} \mathrm{Ga}$-citrate PET/CT for evaluating patients with infections of the bone: preliminary results. J Nucl Med. 2010;51: 1932-1936.

69. Tseng J-R, Chang Y-H, Yang L-Y, et al. Potential usefulness of ${ }^{68}$ Ga-citrate PET/ CT in detecting infected lower limb prostheses. EJNMMI Res. 2019;9:2.

70. Vorster M, Maes A, van de Wiele C, Sathekge M. ${ }^{68} \mathrm{Ga}$-citrate PET/CT in tuberculosis: a pilot study. Q J Nucl Med Mol Imaging. 2019;63:48-55.

71. Petrik M, Haas H, Laverman $\mathrm{P}$, et al. ${ }^{68} \mathrm{Ga}$-triacetylfusarinine $\mathrm{C}$ and ${ }^{68} \mathrm{Ga}$-ferrioxamine $\mathrm{E}$ for aspergillus infection imaging: uptake specificity in various microorganisms. Mol Imaging Biol. 2014;16:102-108.

72. Petrik M, Umlaufova E, Raclavsky V, et al. Imaging of Pseudomonas aeruginosa infection with Ga-68 labelled pyoverdine for positron emission tomography. Sci Rep. 2018;8:15698.

73. Parker MFL, Luu JM, Schulte B, et al. Sensing living bacteria in vivo using dalanine-derived ${ }^{11} \mathrm{C}$ radiotracers. ACS Cent Sci. 2020;6:155-165.

74. Yang R-H, Lee T-H, Chu Y-K. Unexpected thoracic endograft infection following a colorectal procedure. Nucl Med Biomed Imaging. 2016;1:7-9.

75. Truluck CA. Nuclear medicine technology: inflammation and infection imaging. J Radiol Nurs. 2007;26:77-85.

76. ACR-SPR practice parameter for the performance of scintigraphy for inflammation and infection. American College of Radiology website. https://www. acr.org/-/media/ACR/Files/Practice-Parameters/InflamInfScint.pdf. Published 2018. Accessed September 23, 2020.

77. Bartel TB, Kuruva M, Gnanasegaran G, et al. SNMMI procedure standard for bone scintigraphy 4.0. J Nucl Med Technol. 2018;46:398-404. 